\title{
Brown Sequard Syndrome Revealing a Cystic Cervical Spinal Schwannoma: About a Case at the Neurosurgery Clinic of Fann University Hospital in Dakar
}

\author{
BARRY Louncény Fatoumata*, FAYE Mohameth, CISSE Yakhya, NDONGO Mouhamadou \\ Moustapha, MALANGU Mhaks, ADJAMOU Amidou, BA Momar Code, BADIANE Seydou \\ Boubakar \\ Neurosurgery Clinic, Fann University Hospital, Dakar, Senegal
}

*Corresponding Author: BARRY Louncény Fatoumata, Neurosurgery Clinic, Fann University Hospital, P.O. Box: 5035 Dakar, Senegal.

\begin{abstract}
Background and Importance: Cystic schwannomas are rare benign tumors. We report a case of cervical localization, revealed by a Brown Sequard syndrome.

Case Presentation: This is a 53-year-old patient, hypertensive and diabetic. Received in consultation for right hemiparesis and paresthesias of the 4 limbs, preceded by cervico-brachial neuralgia. Cervical magnetic resonance imaging shows a right intradural lesion opposite the C5 vertebra, compressing the spinal cord and requiring posterior excision. Diagnostic confirmation was obtained by anatomopathological examination. The evolution was favorable with almost complete motor recovery and disappearance of the neuralgia.
\end{abstract}

Conclusion: These are rare cases of schwannoma with a rapid and favorable evolution without recurrence after complete resection.

Keywords: Schwannoma; cystic; cervical; hemiparesis.

\section{BACKGROUND AND IMPORTANCE}

First proposed by VEROCAY in 1910, the term neurinoma or schwannoma refers to an encapsulated tumor developed on a root or peripheral nerve trunk at the expense of the Schwann sheath [1]. The cervical location of spinal schwannoma accounts for $22 \%$ of all spinal schwannomas [2]. Most schwannomas are solid and/or heterogeneous tumors, but may rarely undergo cystic degeneration, xanthomatous change or hemorrhage [3]. Their evolution is generally slow, which explains the progressive appearance of clinical signs and may be responsible for spinal and/or root compression [4]. Magnetic resonance imaging (MRI) is used to diagnose the disease and to guide therapy both in terms of indications and choice of approach [4]. Surgery is the first-line treatment for spinal neurinoma [3].

We report a case of cervical cystic schwannoma revealed by cervical Brown Sequard syndrome and treated surgically by total resection.

\section{Case Presentation}

This is a 53-year-old hypertensive and diabetic patient, received in consultation for the progressive installation over 8 months of a right hemiparesis associated with medullary claudication, paresthesia of the 4 limbs more accentuated on the right, with a type of burn and preceded by a right cervico-brachial neuralgia in the territory of $\mathrm{C} 5$ evolving for 2 years. The physical examination found a patient in good general condition, presenting at the neurological examination a right hemiparesis without facial participation rated at $4 / 5$ in the upper limb and $3 / 5$ in the lower limb with proprioceptive disorders of the right half of body (dysarthrokinesia and apallesthesia) and tactile and algetic hypoesthesia of the left half of body.

MRI had revealed a $9 \times 11 \mathrm{~mm}$ intradural mass developed at the posterolateral right part of the spinal canal opposite the $\mathrm{C} 4$ vertebra, in iso signal $\mathrm{T} 1$, hyper signal $\mathrm{T} 2$, heterogeneously enhanced after gadolinium injection and in close contact with the right C5 root (Figure 1). 


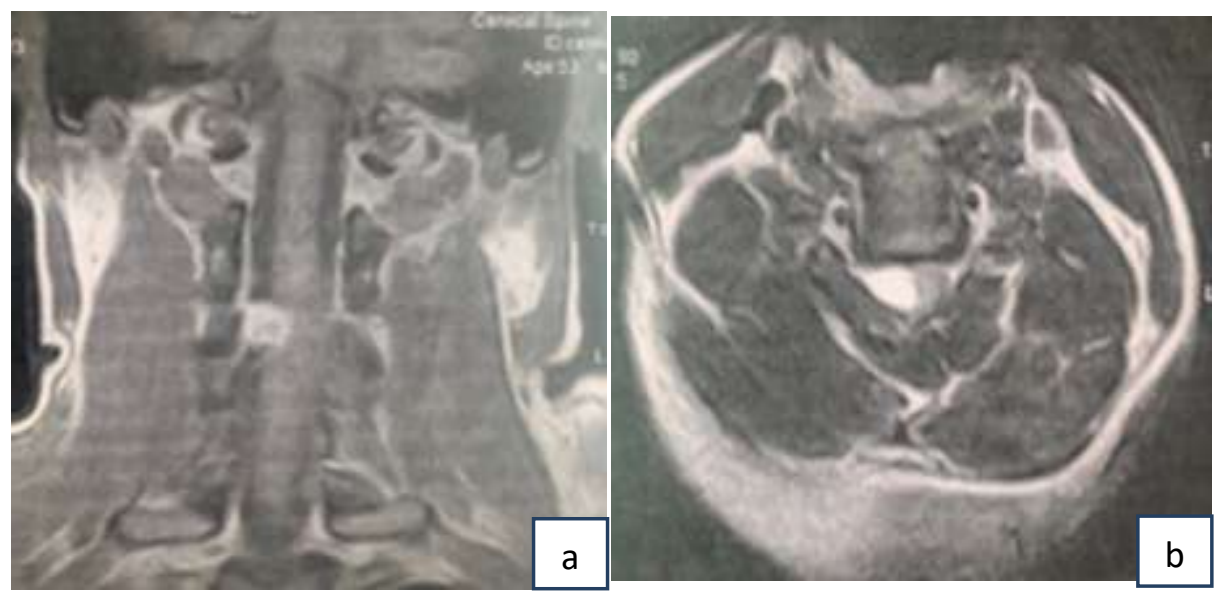

Figure 1. Preoperative Cervical MRI

a) coronal section $T 1+$ gadolinium; b) axial section $T 2$ sequence: right lateral intradural lesion, heterogeneous T1+gadolinium contrast shot and hyper signal T2 with right lateral medullary compression.

The approach was performed posteriorly after laminectomy of C3, C4 and C5, followed by dural opening, revealing an intradural, greyish, cystic mass, compressing the spinal cord pushed to the left and sheathing the dorsal root of C5
(Figure 2). Removal of the capsule and the dorsal root of C5 sheathed by the tumor was completed by removal of the capsule and the dorsal root of C5 sheathed by the tumor after removal of the cyst.

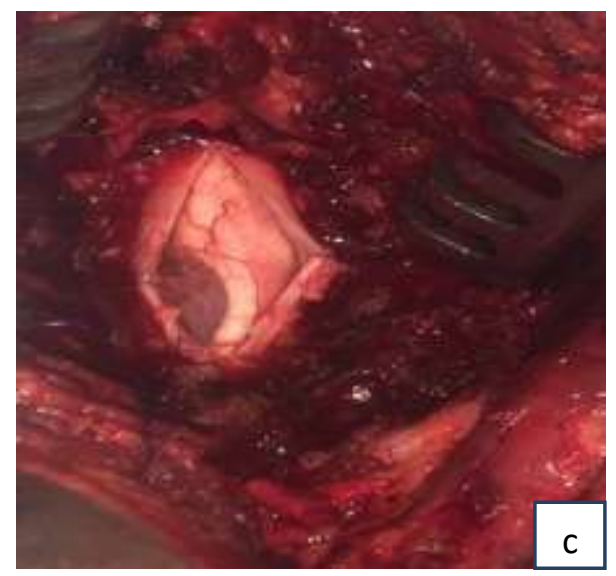

Figure 2. Intraoperative Image

c) greyish, cystic right intradural lesion, compressing the deviated spinal cord to the left

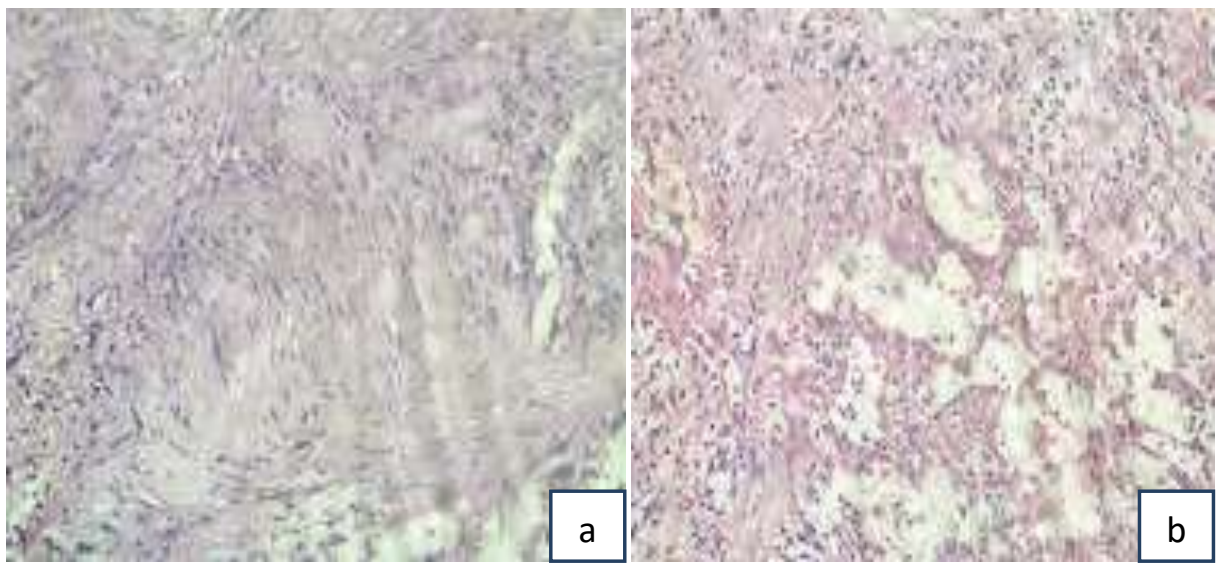

Figure 3. Anatomopathologic Results

a) Antoni A zones b) Antoni B zones 
Anatomopathological examination revealed a benign schwannoma (Figure 3). The evolution after 1 year of regression is marked by the complete regression of cervico-brachial neuralgia with anesthesia in the territory of the right $\mathrm{C} 5$ root and the almost complete recovery of hemiparesis rated 4/5 in the upper limb and $5 / 5$ in the lower limb without tumor residue on postoperative MRI (Figure 4).

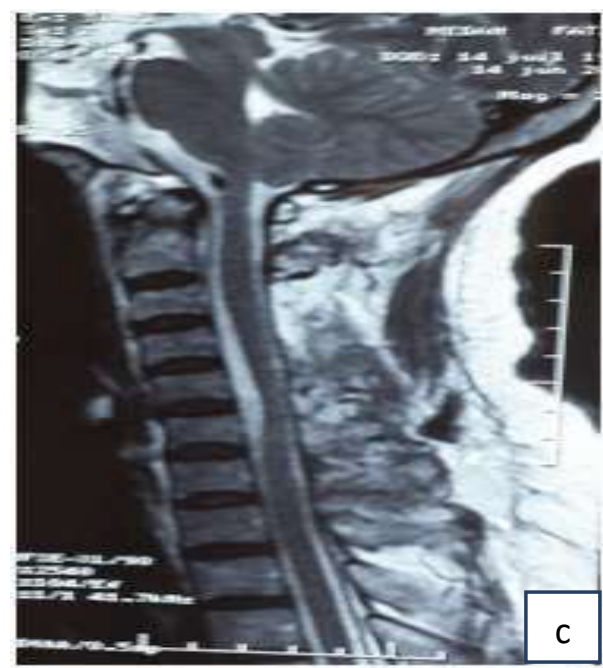

Figure 4. Postoperative MRI

c) Absence of tumor residue

\section{DISCUSSION}

Cervical cystic schwannoma is a very rare, benign, encapsulated tumor developed from cells of the Schwann sheath. Tumor growth is slow and clinical diagnosis is often late [3]. It results in spontaneous pain such as cervical or radiculalgia, paresthesia or numbness in all four limbs that progresses to spinal cord compression [5]. As in the case of our patient whose injury was revealed by a lateral slow spinal cord compression pattern (Brown Sequard syndrome), preceded by right cervico-brachial neuralgia. MRI is currently the examination of choice. It reveals an intradural-extramedullary lesion, hypo-intense in T1 sequence and hyperintense in $\mathrm{T} 2$ with a cystic signal or hemorrhagic foci with a hemosiderin deposit [4] as in our case. The cystic transformation of a schwannoma is extremely rare, and is thought to be due either to degeneration of the Antoni B part of the tumor or to necrosis due to intratumor ischemic attacks [3].

The treatment is exclusively surgical. The goal of the surgical treatment is to achieve complete surgical resection with minimal morbidity and risk of recurrence. This surgery is conceptually required as a matter of urgency in front of a slow radiculomedullary compression table [6]. The surgical approach (posterior, anterior or combined) depends on several elements including the exact level of the lesion, its position in relation to the nervous elements, its possible extra-spinal extension, its vascular ratios and the size of the tumor [6]. In our case, the approach was posterior with laminectomy of C3, C4 and C5 allowing complete exeresis.

The differential diagnosis of a cystic lesion in the spinal canal includes dermoid cyst, squamous cell cyst, arachnoid cyst, bronchogenic cyst, neurenteric cyst, cystic teratoma, tuberculoma and meningioma [3]. The diagnosis is anatomopathological on a surgical specimen, due to the existence of Schwann cells of different morphology and organization, classified according to Antoni in zone A where they appear in bundles, with nuclei aligned in palisade and in zone B of cystic appearance and myxoid nature [7].

The prognosis for schwannomas is excellent. Nerve sequelae are exceptional. Local recurrence is rare and is probably due to incomplete resection. Malignant degeneration is exceptional and even not admitted because a schwannoma would be benign or malignant $[7$, 8].

\section{CONCLUSion}

Cystic cervical schwannoma is a rare, slowgrowing, benign tumor. Surgery has been the exclusive treatment for our patient with a complete resection allowing a good clinical evolution and absence of recurrence. 


\section{FUNDING}

The authors declare that they have received no funding for this work.

\section{DECLARATION OF INTEREST}

The authors declare that they have no conflicts of interest.

\section{REFERENCES}

[1] Coulon A, Milin, Laban E, Debiais C, Jamet C, Goujon J-M Pathologic characteristics of the most frequent peripheral nerve tumors Neurochirurgie 2009 ; 55 ; 454-58

[2] Baldoino M, Borges G, Ferreira A, França D, Patricia Mello. Schwannoma of the craniocervical junction Arq Neuro psiquiatr 2003;61(3-A):639-641.

[3] S. khailia, I. Si Ali, R. kettab, N. mehdi, A. taleb, Dahmouche, Medjamia. Un schwannome kystique cervical géant à propos d'un cas et revue de la littérature. Journal algérien de Neurochirurgie $2015 ; 22$ : 44-47.
[4] Jeon J, Hwang H, Jeong J et al. Spinal Schwannoma: Analysis of 40 Cases. Neurosurg Soc. $2008 ; 43: 135-138$.

[5] Bouaziz M, Derdour S, Laouar O, Lankar A Spinal root of accessory nerve shwannoma: About a new case. Neurochirurgie 2012; (58): 258-262.

[6] Kiyoshi Ito, Tatsuro Aoyama, Yoshinari Miyaoka, Tetsuyoshi Horiuchi, and Kazuhiro Hongo.Surgical Strategies for Cervical Spinal Neurinomas. Neurol Med Chir (Tokyo) 2015; 55: 557-563.

[7] NajibBenmansour, YasineElfadl, Amal Bennani, Mustapha Maaroufi, Leila Chbani1, AfafAmarti et al.Schwannome cervical du nerf vague: Stratégies diagnostique et thérapeutique. Pan AfricanMedical Journal. $2013 ; 14$ : 76.

[8] E.E.M. Nao, O. Dassonville, A. Bozec, A. Sudaka, P.Y. Marcy, N. Vincent et al. Schwannome du sympathique cervical. Annales françaises d'oto-rhino-laryngologie et de pathologie cervico-faciale $2012 ; 129: 60-63$.

Citation: BARRY Louncény Fatoumata et al. Brown Sequard Syndrome Revealing a Cystic Cervical Spinal Schwannoma: About a Case at the Neurosurgery Clinic of Fann University Hospital in Dakar. ARC Journal of Clinical Case Reports. 2020; 6(4):1-4. DOI: https://doi.org/10.20431/2455-9806.0604001.

Copyright: () 2020 Authors. This is an open-access article distributed under the terms of the Creative Commons Attribution License, which permits unrestricted use, distribution, and reproduction in any medium, provided the original author and source are credited. 